\title{
Formulation and In vitro Characterization of Hydrochlorothiazide Gastroretentive Floating Drug Delivery System
}

\section{Md. Asif Hasan ${ }^{1}$, Sabiha Sultanaㄹ, Sujan Banik ${ }^{1}$, Md. Masud Kaisar Bhuiyan ${ }^{1}$, Md. Selim Reza ${ }^{3}$ and Mohammad Salim Hossain ${ }^{1}$}

\author{
${ }^{1}$ Department of Pharmacy, Noakhali Science and Technology University, Sonapur, Noakhali-3814, Bangladesh \\ ${ }^{2}$ Department of Pharmacy, University of Asia Pacific, Dhaka-1207, Bangladesh \\ ${ }^{3}$ Department of Pharmaceutical Technology, University of Dhaka, Bangladesh
}

Received: November 24, 2014; Accepted: January 17, 2016; Published (web): January 31, 2016

\begin{abstract}
The purpose of the study was to develop and optimize floating bioadhesive gastroretentive drug delivery system (GRDDS) exhibiting a unique combination of floatation and bioadhesion to prolong residence in the stomach, using hydrochlorothiazide (HCTZ) as a model drug. Formulated matrix tablets were prepared by direct compression method with two different rate controlling polymer HPMC K4M and Carbopol 971. The formulated tablets were evaluated for physical characterization, floating lag time, swelling index and drug content uniformity. The drug release study was carried out in $0.1 \mathrm{~N} \mathrm{HCl}$ as the medium $(\mathrm{pH} 1.2)$ for 8 hours using USP type II dissolution apparatus and investigated the effects of polymers on the drug release profile. In vitro buoyancy study results found to be 10-33 sec and $>8 \mathrm{~h}$, floating lag time and total floating time respectively. Simulated drug release pattern in different kinetic models of Korsmeyer-Peppas release suggests that the mechanism controlling of the drug release from all formulations was the anomalous non-Fickian or anomalous release. Polymer with lower viscosity (HMPC K4M) was found to be beneficial than higher viscosity polymer (Carbopol 971) in improving the release properties of gastric floating drug delivery system. Incorporation of Carbopol in formulation also helped in maintaining buoyancy of system with desirable drug release. Further study is necessary in case of in vitro-in vivo relationship, but this study will ready to lend a hand to future scientists working in this field to successfully exploit the potential of this drug delivery system for the advantage of mankind.
\end{abstract}

Key words: Hydrochlorothiazide, HPMC K4M, Carbopol 971, GRDDS

\section{INTRODUCTION}

Various types of oral controlled release formulation have been developed to improve the clinical efficacy of drugs having short half-lives as well as to increase patient compliance. These formulations are designed to deliver drugs at a predetermined rate over a wide range of conditions and durations of therapeutic treatments. Over the last three decades, a variety of approaches have been pursued to increase the retention of an oral dosage form in the stomach, like floating drug delivery system (FDDS) ${ }^{1}$ expanding and swelling systems ${ }^{2}$

Correspondence to: Mohammad Salim Hossain Cell: +88-01711-200410

Email: pharmasalim@yahoo.com

Dhaka Univ. J. Pharm. Sci. 14(2): 163-170, 2015 (December) high density system $^{3}$ modified shape system $^{4}$ bioadhesive system $^{5}$ and other delayed gastric empting device. ${ }^{6}$ Detailed studies on controlled drug delivery system reported that, FDDS is a gastroretentive dosage from (GRDF), which is considerably easy and reasonable approach to prolong the gastric residence time (GRT) in extending an optimum drug bioavailability. ${ }^{7}$ Effervescent FDDS and non-effervescent FDDS, two different technologies are attempted to release drug in case of floating drug delivery system based on mechanisms. In case of effervescent system, when the drug reaches in stomach $\mathrm{CO}_{2}$ is liberated by the acidity of gastric substance and is entrapped in jellified hydro colloid. This liberated gas, if expelled 
from the dosage form, creates pores through which water can easily pass and helps in wetting of the polymers through sustaining the release drug. Conversely, non-effervescent floating dosage forms are formulated by using gel forming or swellable cellulose type of hydrocolloids, polysaccharides, and matrix-forming polymers like polycarbonate, polyacrylate, polymethacrylate, and polystryrene.

HCTZ is a diuretic of the bezothiadiazine class and has proved very important in the management of mild to moderate hypertension. It inhibits sodium reabsorption in distal tubules causing increased excretion of sodium and water as well as potassium and hydrogen ions. Hydrochlorothiazide is a poorly water soluble drug having plasma half-life of 6-8 hrs and oral bioavailability is $70 \%$. It is mainly absorbed from the upper part of the duodenum and if any reason it passes this absorption site, there is no absorption take place. ${ }^{9}$

The present study was undertaken with the objective to develop an optimized FDDS containing HCTZ as a model drug to improve absorption and its oral bioavailability. In the current study the effect of polymer (HPMC K4M and Carbopol 971), polymer concentration and viscosity on drug release behavior and the buoyancy properties of prepared formulations were evaluated.

\section{MATERIALS AND METHODS}

Materials. Hydrochlorothiazide was used as a model drug which was obtained as a gift sample from
Drug International Ltd, Bangladesh. Polymer HPMC K4M, Carbopol 971 and all other materials were obtained as gift samples from the University of Asia Pacific (UAP), Bangladesh. All of the chemicals used in this experiment were of analytical reagent grade and distilled water was used throughout the experiment.

Preparation of floating matrix tablet. Floating tablets, each containing $50 \mathrm{mg}$ Hydrochlorothiazide were prepared by direct compression method. The composition of all formulations of this study was shown in table 1 . The active ingredient and other excipients were weighed accurately for twenty five tablets according to the formulations and collected in mortar pastle. After proper mixing $(5 \mathrm{~min})$ it was passed through the sieve no. 40 and collected in polyethylene bag. Individually weighed the amount of granules for each tablet $(450 \mathrm{mg})$ and compressed by using a Perkin-Elmer laboratory hydraulic press equipped with a $10 \mathrm{~mm}$ flat faced die and punch set. The compression force (5 tons) was applied and compression time was $1.00 \mathrm{~min}$ for every tablet. Before compression, the surface of the die and punch were lubricated with magnesium stearate. Airtight photo film containers were used for all preparations for storage at room temperature. The technique for tablet production was followed as mentioned by Sato et al. ${ }^{10}$ and Hossain et al. ${ }^{11}$ that provided reproducible experimental results in terms of in-vitro release.

Table 1. Formulation of Hydrochlorothiazide with two different polymers.

\begin{tabular}{lcccccccccccc}
\hline Ingredients $(\mathrm{mg})$ & $\mathrm{F} 1$ & $\mathrm{~F} 2$ & $\mathrm{~F} 3$ & $\mathrm{~F} 4$ & $\mathrm{~F} 5$ & $\mathrm{~F} 6$ & $\mathrm{~F} 7$ & $\mathrm{~F} 8$ & $\mathrm{~F} 9$ & $\mathrm{~F} 10$ & $\mathrm{~F} 11$ & $\mathrm{~F} 12$ \\
\hline HCTZ & 50 & 50 & 50 & 50 & 50 & 50 & 50 & 50 & 50 & 50 & 50 & 50 \\
HPMC K4M & 100 & 120 & 140 & 160 & 180 & 200 & - & - & - & - & - & - \\
Carbopol 971 & - & - & - & - & - & - & 100 & 120 & 140 & 160 & 180 & 200 \\
NaHCO $_{3}$ & 50 & 50 & 50 & 50 & 50 & 50 & 50 & 50 & 50 & 50 & 50 & 50 \\
Citric acid & 50 & 50 & 50 & 50 & 50 & 50 & 50 & 50 & 50 & 50 & 50 & 50 \\
Povidon K30 & 20 & 20 & 20 & 20 & 20 & 20 & 20 & 20 & 20 & 20 & 20 & 20 \\
Avicel PH 102 & 170 & 150 & 130 & 110 & 90 & 70 & 170 & 150 & 130 & 110 & 90 & 70 \\
Mg stearate & 5 & 5 & 5 & 5 & 5 & 5 & 5 & 5 & 5 & 5 & 5 & 5 \\
Purified talc & 5 & 5 & 5 & 5 & 5 & 5 & 5 & 5 & 5 & 5 & 5 & 5 \\
\hline Total & $\mathbf{4 5 0}$ & $\mathbf{4 5 0}$ & $\mathbf{4 5 0}$ & $\mathbf{4 5 0}$ & $\mathbf{4 5 0}$ & $\mathbf{4 5 0}$ & $\mathbf{4 5 0}$ & $\mathbf{4 5 0}$ & $\mathbf{4 5 0}$ & $\mathbf{4 5 0}$ & $\mathbf{4 5 0}$ & $\mathbf{4 5 0}$ \\
\hline
\end{tabular}


Drug content and evaluation of physical characterization. The drug content of the formulated tablets of each formulation was estimated using $0.1 \mathrm{M}$ sodium hydroxide and the sample was analyzed by using a double beam UV-Visible spectrophotometer (UV-1800 Shimadzu) at $272 \mathrm{~nm}$. The formulated tablets were evaluated for thickness, hardness, friability, weight variation with regards their British Pharmacopeia specification. ${ }^{11}$

In vitro buoyancy study. The time required for dosage form to emerge of medium called buoyancy lag time (BLT) or floating lag time (FLT). Duration of time by which the dosage forms constantly emerges on surface of a medium called total floating time (TFT). The prepared tablets were subjected to in vitro buoyancy test by placing them in $100 \mathrm{~mL}$ glass beaker containing $0.1 \mathrm{~N} \mathrm{HCl}\left(\mathrm{pH} 1.2\right.$, temp. $37 \pm 0.5^{\circ}$ C) as per USP. The time required for the tablet to rise to the surface and float was determined at floating lag time and the time for which a tablet constantly floats on the surface of the medium was calculated for the determination of total floating time. ${ }^{12}$

Swelling index. Swelling of tablet excipients particles involves the incorporation of a liquid resulting in an increase in weight and volume. Liquid uptake by the particle may be owing to saturation of capillary spaces inside the particles or hydration of macromolecule. The liquid passed the particles through pores and bound to large molecule; breaking the hydrogen bond and resulting in the swelling of particle. Weight gain by the tablet is a technique used for measuring the extent of swelling. For determination of swelling index, each tablet from all formulations pre-weighed and placed in a beaker containing $100 \mathrm{ml}$ of $0.1 \mathrm{~N} \mathrm{HCl}$ at room temperature. After each hour the tablet was removed from beaker and weighed again up to 5 hours. ${ }^{13}$ The swelling index was then calculated using the formula:

Swelling Index $=\frac{\left(\mathrm{W}_{\mathrm{t}}-\mathrm{W}_{0}\right)}{\mathrm{W}_{0}} \times 100$

where, $\mathrm{W}_{\mathrm{t}}=$ weight of tablet at time $\mathrm{t} ; \mathrm{W}_{\mathrm{o}}=$ initial weight of tablet.
In vitro drug release studies. The in-vitro release of HCTZ from the formulated tablets was carried out in USP type II apparatus using $900 \mathrm{~mL}$ of dissolution medium maintained at $37.0 \pm 0.5^{\circ} \mathrm{C}$ and a stirring rate of $75 \mathrm{rpm}$. Triplicate basket system was considered for dissolution studies using $900 \mathrm{~mL}$ of $0.1 \mathrm{~N} \mathrm{HCl}(\mathrm{pH} 1.2)$ as a dissolution medium for the following 8 hours. At specific time interval aliquots of $10 \mathrm{~mL}$ was withdrawn for measuring the drug release and in every case $10 \mathrm{~mL}$ of fresh dissolution medium was substituted to maintain the volume constant. After filtration, the amount of Hydrochlorothiazide in each sample was determined spectrophotometrically at $272 \mathrm{~nm} .^{6}$

Analysis of release data. The release data obtained were treated according to zero-order (cumulative amount of drug release versus time (hr)), first order (log cumulative percentage of drug remaining versus time (hr)), Higuchi (cumulative percentage of drug release versus square root of time (hr)), Korsmeyer-Peppas (log cumulative percentage of drug release versus log time (hr)) equation models. Korsmeyer-Peppas et al. ${ }^{14}$ has introduced a wellknown exponential equation, which is often used to narrate the drug release behavior form polymeric systems. This equation was applied in this study to analyze the resulting dissolution data.

$$
\mathrm{M}_{\mathrm{t}} / \mathrm{M}_{\infty}=\mathrm{k} \mathrm{t}^{\mathrm{n}}
$$

where, $\mathrm{M}_{\mathrm{t}}$ is the amount of drug release at time $\mathrm{t}$, $\mathrm{M}_{\infty}$ is the amount of drug release after infinite time; $\mathrm{k}$ is a release rate constant incorporating structural and geometric characteristics of the tablet and $\mathrm{n}$ is the diffusional exponent indicative of the mechanism of drug release. A value of $n=0.45$ indicates Fickian (case I) release, $>0.45$ but $<0.89$ for non-Fickian (anomalous) release and $>0.89$ indicates super case II type of release. Cass II normally indicates the erosion of the polymeric chain and anomalous transport (non-Fickian) is a combination of both diffusion and erosion controlled-drug release. ${ }^{15}$

Mean dissolution time (MDT) was calculated from dissolution data using the following equation (Mockel and Lippold). ${ }^{16}$ 


$$
\text { MDT }=(n / n+1) k^{-1 / n}
$$

where, $\mathrm{n}$ is the release exponent and $\mathrm{k}$ is the release rate constant.

\section{RESULTS AND DISCUSSION}

Physical characterization and drug content of floating tablets. The prepared tablets were subjected to preliminary characterization such as physical parameters (thickness, diameter, hardness and friability) and weight uniformity of all the fabricated tablets. The values are presented in Table 2. Table 2 also shows the drug content of these tablets. All the batches showed uniform thickness and diameter. The percentage of average weight deviation of 10 tablets of each formulation was less than (5\%), and hence all formulations passed the test for uniformity of weight as per official requirements. The hardness of the tablets of all the formulations ranged from $4.75 \pm$ 0.16 to $6.43 \pm 0.11 \mathrm{kgf}$ showed an acceptable range of limit. In this study, the percentage friability for all the formulations was below $1 \% \mathrm{w} / \mathrm{w}$, indicating that the friability is within the prescribed limits. The prescribed drug content of all the formulations showed good uniformity and this range of drug content among different batches showed from $97.30 \%$ to $99.78 \%$.

Table 2. Tablet properties of the different formulations of HCTZ floating tablets.

\begin{tabular}{|c|c|c|c|}
\hline \multirow[t]{2}{*}{ Batch code } & \multicolumn{3}{|c|}{ Parameters } \\
\hline & Diameter $(\mathrm{mm}) \quad(\mathrm{n}=3)$ & Friability (\%) & Drug content $(\%)$ \\
\hline F-1 & 13 & 0.09 & 99.15 \\
\hline $\mathrm{F}-2$ & 13 & 0.21 & 98.45 \\
\hline F-3 & 13 & 0.35 & 98.60 \\
\hline $\mathrm{F}-4$ & 13 & 0.34 & 98.45 \\
\hline F-5 & 13 & 0.27 & 99.78 \\
\hline F-6 & 13 & 0.31 & 97.45 \\
\hline F-7 & 13 & 0.28 & 98.47 \\
\hline $\mathrm{F}-8$ & 13 & 0.18 & 97.30 \\
\hline F-9 & 13 & 0.08 & 99.40 \\
\hline F-10 & 13 & 0.22 & 99.21 \\
\hline $\mathrm{F}-11$ & 13 & 0.41 & 99.65 \\
\hline F-12 & 13 & 0.26 & 97.40 \\
\hline
\end{tabular}

Table 3. In vitro buoyancy and swelling index study of formulations F1-F6 containing HPMC K4M.

\begin{tabular}{cccc}
\hline $\begin{array}{c}\text { Batch } \\
\text { code }\end{array}$ & $\begin{array}{c}\text { Floating lag } \\
\text { time (sec) }\end{array}$ & $\begin{array}{c}\text { Swelling } \\
\text { index after 5 } \\
\text { hr }\end{array}$ & $\begin{array}{c}\text { Total floating } \\
\text { time (hr) }\end{array}$ \\
\hline F-1 & 33 & $82.21 \%$ & $>6$ \\
F-2 & 20 & $89.99 \%$ & $>6$ \\
F-3 & 28 & $100.75 \%$ & $>6$ \\
F-4 & 16 & $113.05 \%$ & $>6$ \\
F-5 & 21 & $127.70 \%$ & $>8$ \\
F-6 & 29 & $128.43 \%$ & $>8$ \\
\hline
\end{tabular}

Table 4. In vitro buoyancy and swelling index study of formulations F7-F12 containing Carbopol.

\begin{tabular}{cccc}
\hline $\begin{array}{c}\text { Batch } \\
\text { code }\end{array}$ & $\begin{array}{c}\text { Floating lag } \\
\text { time }(\mathrm{sec})\end{array}$ & $\begin{array}{c}\text { Swelling index } \\
\text { after 5 hr }\end{array}$ & $\begin{array}{c}\text { Total floating } \\
\text { time }(\mathrm{hr})\end{array}$ \\
\hline F-7 & 18 & $73.23 \%$ & $>6$ \\
F-8 & 13 & $81.67 \%$ & $>6$ \\
F-9 & 22 & $93.75 \%$ & $>8$ \\
F-10 & 15 & $104.05 \%$ & $>8$ \\
F-11 & 19 & $115.90 \%$ & $>8$ \\
F-12 & 10 & $121.27 \%$ & $>8$ \\
\hline
\end{tabular}

In vitro buoyancy and swelling studies. HPMC and Carbopol was selected as a polymer considering its widespread applicability in controlled release drug formulation and excellent gelling activity in formulations along with safety, effectiveness, cost and availability. Sodium bicarbonate generates $\mathrm{CO}_{2}$ gas in the presence of $\mathrm{HCl}$ acid present in dissolution medium. The generated gas is trapped and confined within the gel, thus decreasing the density of the tablet. When the density of the tablet falls below 1 (density of water), then the tablet becomes buoyant. From the present study it was reported that FLT is elevated for the formulations containing retardant polymer like HPMC K4M and Carbopol 971. Total Floating Time is better when the amount of polymer is gradually increased (Table 3 and Table 4). All formulations showed good buoyancy properties due to their low density than GI fluid. Formulation 
containing carbopol 971 (F7-F12) showed good floating behavior than formulation containing HPMC K4M (F1-F6).

Water uptake by the tablets was used as process of swelling of polymers that was determined. The percent swelling of the tablet was determined at the end of 5 hrs (Figure 1) increase in percent swelling was found with increasing concentration of polymers.
Though both formulations containing HPMC K4M and carbopol971 have the same concentration of polymer but HPMC K4M stores more water than carbopol 971. The swelling index was highest for tablets of formulation F6 (128.43\%) than in F12 $(121.27 \%)$. This indicates that HPMC stores more water content in matrix than Carbopol 971.

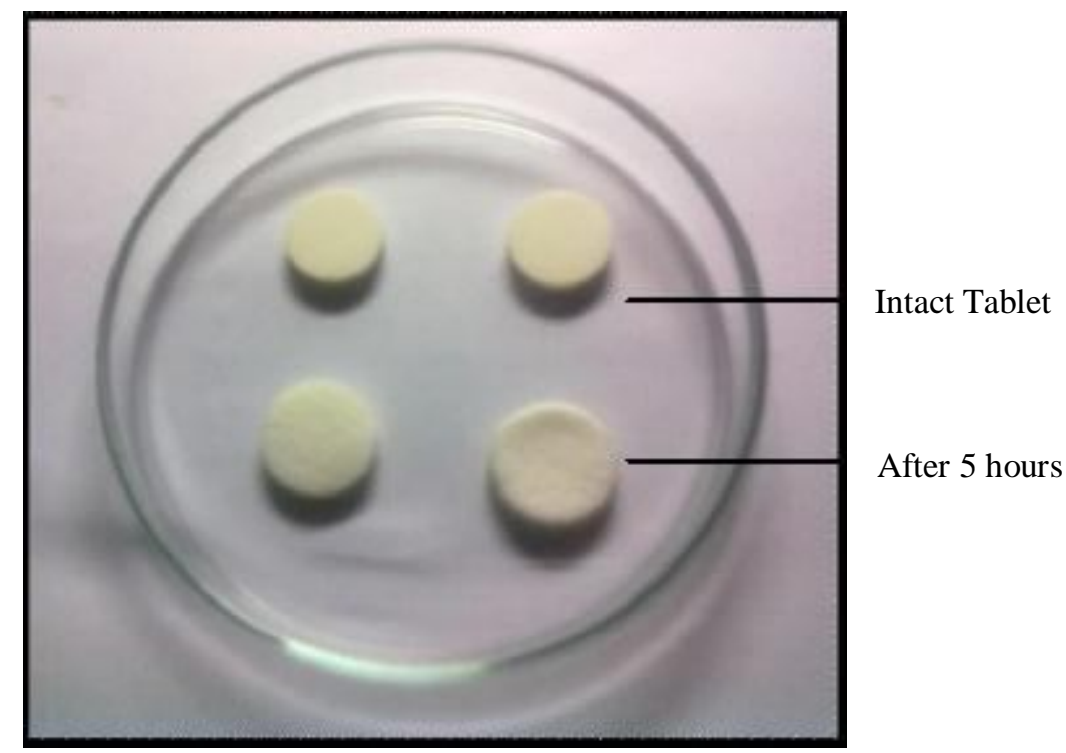

Figure 1. Photographic images showing water uptake by the tablets.

Release kinetic studies. The dissolution data of all formulations were fitted to various mathematical models such as zero-order, first-order, Higuchi, Korysmeyer and Peppas model to know which mathematical model will best fit for the obtained release profile. The cumulative percentage of drug release after 8 hours of all formulations and the release parameters of all formulations are presented in Table 5. The release profile of promising batch, F6, fitted best to zero order with $r^{2}$ value of 0.992 (Figure 2). Based on the ' $n$ ' values ranging from 0.45 $<\mathrm{n}<0.89$ the drug release was found to follow anomalous or non-Fickian release. This numerical value indicates is a coupling process of the diffusion and erosion mechanism and that the process was controlled by more than one process. The finding results of this study was in harmony with other published works. ${ }^{17,18}$
The dissolution studies of in-vitro of formulations F1 to F12 indicated that as the polymer concentration and viscosity was increased, there was a reduction in the drug release. Formulations containing polymer HPMC $\mathrm{K} 4 \mathrm{M}$ (F1 to F6) has higher drug release when compared to formulations having polymer Carbopol 97 (F7 to F12) (Figure 3). The amount of drug release from formulated formulation was found to be in order of $\mathrm{F} 1>\mathrm{F} 2>\mathrm{F} 3>\mathrm{F} 4>\mathrm{F} 5>\mathrm{F} 6 \quad$ and $\mathrm{F} 7>\mathrm{F} 8>\mathrm{F} 9>\mathrm{F} 10>\mathrm{F} 11>$ F12 in two cases of polymer concentration. Increasing polymer concentration causes decreasing drug release rate of all formulated formulations of floating tablets. 
Table 5. Cumulative percentage release (CPR) and release kinetics parameter of formulated floating tablets of HCTZ.

\begin{tabular}{|c|c|c|c|c|c|c|}
\hline \multirow[t]{2}{*}{ Formulations } & \multirow[t]{2}{*}{ CPR* } & \multirow{2}{*}{$\frac{\text { Zero order }}{\mathrm{R}^{2}}$} & \multirow{2}{*}{$\begin{array}{r}\text { First order } \\
\mathrm{R}^{2}\end{array}$} & \multirow{2}{*}{$\begin{array}{r}\text { Higuchi } \\
\mathrm{R}^{2}\end{array}$} & \multicolumn{2}{|c|}{ Korsmeyar-Peppas } \\
\hline & & & & & $\mathrm{R}^{2}$ & $\mathrm{n}$ \\
\hline F1 & 58.67 & 0.991 & 0.986 & 0.949 & 0.960 & 0.668 \\
\hline F2 & 54.23 & 0.975 & 0.991 & 0.981 & 0.997 & 0.646 \\
\hline F3 & 44.84 & 0.979 & 0.99 & 0.967 & 0.989 & 0.721 \\
\hline F4 & 37.38 & 0.971 & 0.984 & 0.969 & 0.993 & 0.781 \\
\hline F5 & 37.32 & 0.990 & 0.994 & 0.958 & 0.997 & 0.806 \\
\hline F6 & 37.23 & 0.992 & 0.987 & 0.934 & 0.989 & 0.829 \\
\hline F7 & 34.80 & 0.969 & 0.986 & 0.988 & 0.994 & 0.705 \\
\hline F8 & 34.17 & 0.986 & 0.995 & 0.987 & 0.990 & 0.700 \\
\hline F9 & 33.80 & 0.986 & 0.993 & 0.971 & 0.999 & 0.741 \\
\hline F10 & 31.40 & 0.965 & 0.981 & 0.969 & 0.998 & 0.775 \\
\hline F11 & 31.09 & 0.958 & 0.975 & 0.989 & 0.998 & 0.678 \\
\hline $\mathrm{F} 12$ & 27.61 & 0.957 & 0.973 & 0.987 & 0.999 & 0.678 \\
\hline
\end{tabular}

*CPR of drug after 8 hours

Table 6. Required time for $25,50,75$ percentage of drug release and MDT.

\begin{tabular}{cllll}
\hline Formulations & $\mathrm{T}_{25 \%}$ & $\mathrm{~T}_{50 \%}$ & $\mathrm{~T}_{75 \%}$ & $\mathrm{MDT}(\mathrm{hr})$ \\
\hline F1 & 1.495 & 2.695 & 3.895 & 4.49 \\
F2 & 1.465 & 2.723 & 3.982 & 4.36 \\
F3 & 1.799 & 3.313 & 4.826 & 10.36 \\
F4 & 2.006 & 3.712 & 5.419 & 12.09 \\
F5 & 2.139 & 3.938 & 5.736 & 12.49 \\
F6 & 2.208 & 4.033 & 5.858 & 18.73 \\
F7 & 2.597 & 4.990 & 6.128 & 16.98 \\
F8 & 2.430 & 4.662 & 6.358 & 14.83 \\
F9 & 2.313 & 4.335 & 6.518 & 14.56 \\
F10 & 2.377 & 4.450 & 6.678 & 17.07 \\
F11 & 2.361 & 4.519 & 6.894 & 15.07 \\
F12 & 2.181 & 4.154 & 7.384 & \\
\hline
\end{tabular}

In this present study, two polymers HPMC K4M and Carbopol 971 were used in formulated HCTZ floating tablets to evaluate whether any change in release pattern due to polymer types. HPMC is a hydrophilic polymer and most widely used for controlled-release drug formulations. The release of drug from HPMC K4M based floating tablets was more than Carbopol based tablets. Drug release decreased with increase of polymer loading as HPMC polymers form viscous gelatinous layer (gel layer) upon exposure to aqueous medium by undergoing rapid hydration and chain relaxation and this gel layer acts as the barrier to release of drug and as a result drug release is prolonged. On the other hand Carbomers are synthetic high-molecular-weight polymers of acrylic acid and they are readily waterswellable polymers. Carbopol 971 containing tablets showed better controlled release when compared to
HPMC K4M. Formulation containing carbopol 971 also showed decrease of drug release with the increase of amount of polymer.

From the present study, it is clear that $\mathrm{T}_{25 \%}, \mathrm{~T}_{50 \%}$ and $\mathrm{T}_{75 \%}$ values were changed due to the change of the amount of HPMC K4M and Carbopol 971 in the floating tablets (Table 6). In all these formulations, the values of $\mathrm{T}_{50 \%}$ and $\mathrm{T}_{75 \%}$ are larger for those formulations which contain larger quantities of HPMC K4M and Carbopol 971. This observation draws an important conclusion that the increase of HPMC K4M and Carbopol 971 content causes the decrease of rate and extent of HCTZ release. In all cases, the increase of the amount of HPMC K4M causes less release of drug in dissolution study which is supported by the values of T50\%. 

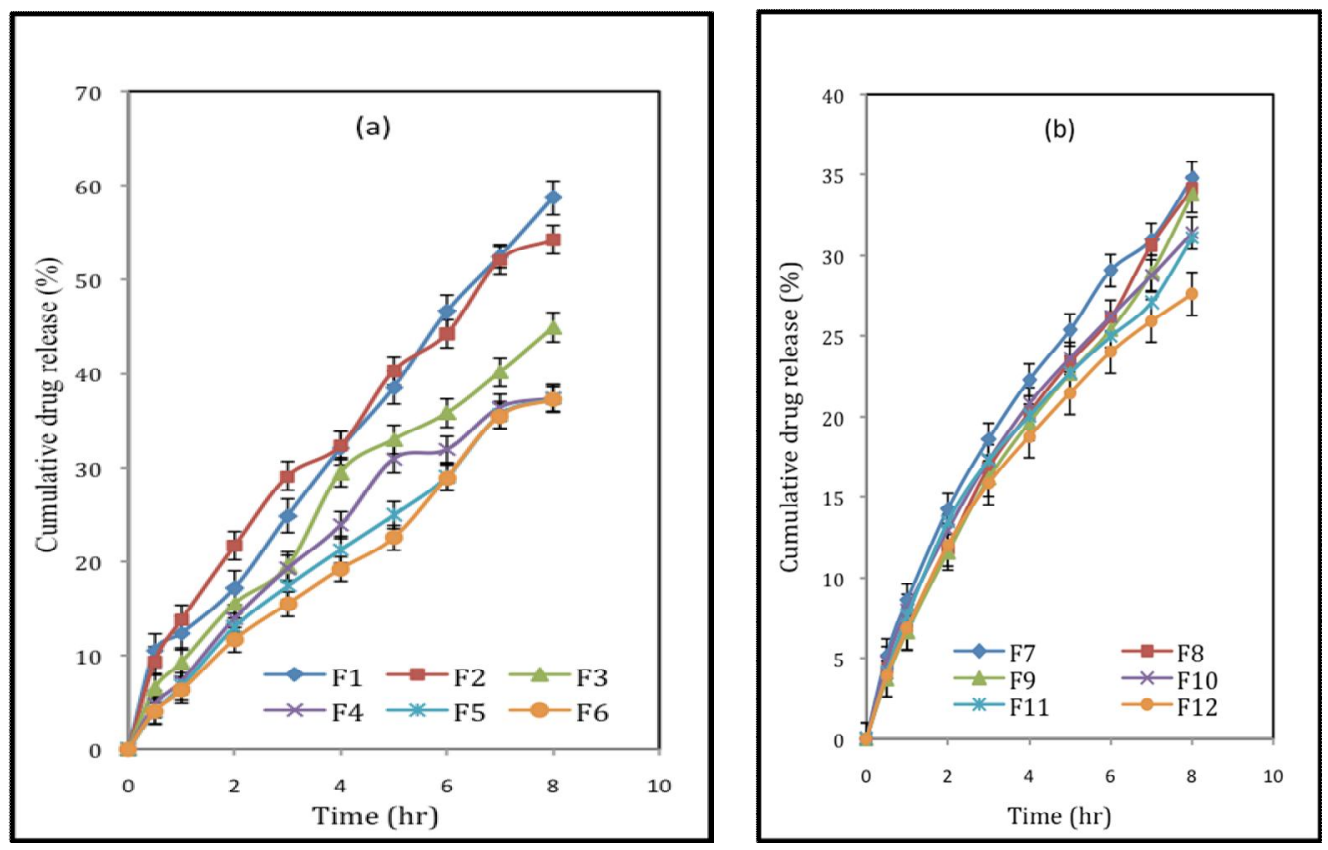

Figure 2. Dissolution release model of HCTZ floating tablets containing (a) HPMC K4M and (b) Carbopol 971.

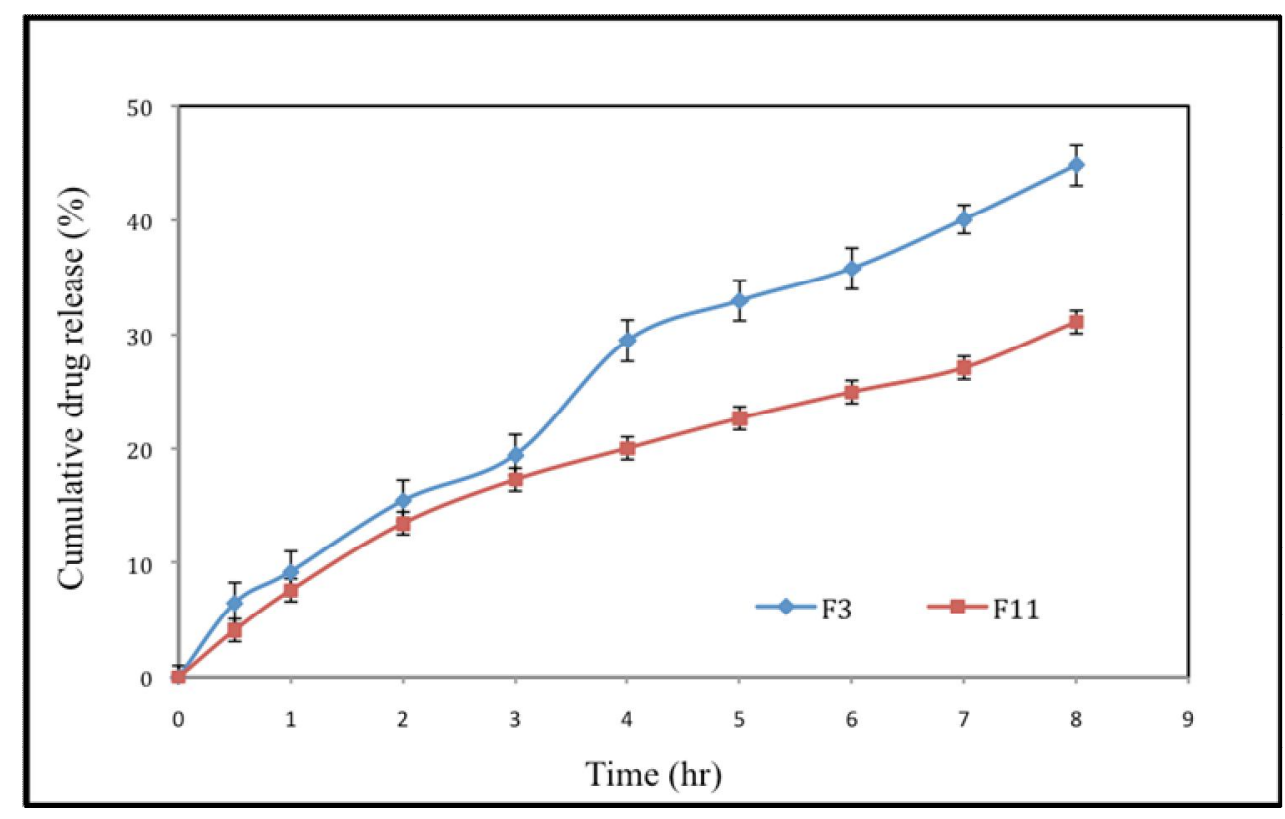

Figure 3. Effect of polymer concentration and viscosity (HPMC K4M and Carbopol 971) on drug releasee rate.

Mean Dissolution Time (MDT) value is used to characterize the drug release rate from the dosage form and the retarding efficacy of the polymer. A high value of MDT indicates a long retarding ability and vice-versa. This MDT value was found to below for formulation $\mathrm{F} 2$ and high for formulation F7 (Table 6). In other words, the formulations containing higher percentage of polymer exhibited a higher value of MDT. 


\section{CONCLUSION}

From the study, it is possible to conclude that the floating dosage forms enable prolonged and continuous input of the drugs to the upper part of the gastrointestinal tract and improve the bioavailability of medications that are characterized by a narrow absorption window. The study reveals that, the proposed tablet formulations were suitable for direct compression method and the incorporation of HPMC K4M and Carbopol 971 as rate controlling polymer showed the good relation between buoyancy and drug release rate. This provides a good scope for scientists working in this area to effectively use the potential of this drug delivery system for the benefit of mankind.

\section{REFERENCES}

1. Liu, Q. and Fassihi, R. 2008. Zero-order delivery of a highly soluble, low dose drug alfuzosin hydrochloride via gastroretentive system. Int. J. Pharm. 348, 27-34.

2. Chen, J. and Park, K. 2000. Synthesis of fast-swelling, superporous sucrose hydrogels. Carbohydr. Polym. 41, 259268.

3. Bardonnet, P., Faivre, V. and Pugh, W. 2006. Gastroretentive dosage forms: overview and special case of Helicobacter pylori. J. Control. Release. 111, 1-18.

4. Klausner, E.A., Eran, L. and Michael, F. 2003. Expandable gastroretentive dosage forms. J. Control. Release. 90, 143162.

5. Lee, J.W., Park, J.H. and Robinson, J.R. 2000. Bioadhesivebased dosage forms: the next generation. J. Pharm. Sci. 89, 850-866.

6. Alexander, S., Juergen, S. and Roland, B. 2006. Drug delivery to the upper small intestine window using gastroretentive technologies. Curr. Opin. Pharmacol. 6, 501508
7. Whitehead, L., Fell, J.T. and Sharma, H.L. 1998. Floating dosage forms: an in vivo study demonstrating prolonged gastric retention. J. Control. Release. 55, 3-12.

8. Hardman, J.G., Limbird, L.E. and Gilman, A.G. 2001. The Pharmacological Basis of Therapeutics. New York, McGraw Hill. p.774.

9. James, W.A. Expandable gastric retention device. 2004, US Patent US2004/0219186A1.

10. Shato, H., Miyagawa, Y. and Okabe, T. 1997. Dissolution mechanism of diclofenac sodium from wax matrix granules. J. Pharm. Sci. 86, 929-934.

11. Hossain, M.S., Banik, S. and Islam, M.S. 2012. Formulation Design and Characterization of Kollidon SR Based Trimetazidine Dihydrochloride Matrix Tablets. Ind. J. Pharm. Edu. Res. 46, 136-144.

12. Rosa, M., Zia, H. and Rhodes, T. 1994. Design and testing in vitro of a bioadhesive and floating drug delivery system for oral application. Int. J. Pharm. 105, 65-70.

13. Colombo, P., Bettini, R., Santi, P., Ascentiis, De.A. and Peppas, N.A. 1996. Analysis of the swelling and releasemechanisms from drug delivery systems with emphasis on drug solubility and water transport. J. Control. Rel. 39, 231 - 237.

14. Korsmeyer, R.W., Gurny, R. and Peppas, N.A. 1983. Mechanism of solute release from porous hydrophilic polymers. Int. J. Pharm. 15, 25-35.

15. Shato, H., Miyagawa, Y. and Okabe, T. 1997. Dissolution mechanism of diclofenac sodium from wax matrix granules. J. Pharm. Sci. 86, 929-934.

16. Mockel, J.E. and Lippold, B.C. 1993. Zero-order release from hydrocolloid matrices. Pharm. Res. 10, 1066-1070.

17. Ritger, P.L. and Peppas, N.A. 1987. A simple equation for description of solute release II. Fickian and anomalous release from swellable devices. J. Control. Rel. 5, 37-42.

18. Gupta, A.K. 1994. Introduction to Pharmaceutics-I. CBS publishers, Delhi. 3rd edn. pp. 267- 268. 